\title{
AKTIVITAS ANTIBAKTERI EKSTRAK KULIT BAWANG MERAH (Allium cepa L.) TERHADAP BAKTERI Staphylococcus aureus
}

\section{ANTIBACTERIAL ACTIVITY EXTRACT OF GARLIC (Allium cepa L.) SKIN AGAINST Staphylococcus aureus}

\author{
Misna $^{1}$, Khusnul Diana ${ }^{2 *}$ \\ ${ }^{1}$ Akademi Farmasi Tadulako Farma, Palu, Indonesia \\ ${ }^{2}$ Jurusan Farmasi, FMIPA, Universitas Tadulako, Palu, Indonesia
}

Received 28 Agustus 2016, Accepted 28 September 2016

\begin{abstract}
ABSTRAK
Salah satu tanaman yang juga digunakan dalam pengobatan yaitu bawang merah (Allium cepa L.). Selain digunakan sebagai pengobatan dapat juga digunakan sebagai bumbu masakan, bawang merah hanya dimanfaatkan bagian umbinya saja,sedangkan kulit bawang merah yang kaya serat dan flavonoid dibuang. Penelitian ini dilakukan untuk mengetahui apakah kulit bawang merah memiliki aktivitas antibakteri terhadap Staphylococcus aureus. Kulit bawang merah dibuat esktrak dengan metode maserasi menggunakan etanol $96 \%$. Uji aktivitas antibakteri dilakukan dengan metode difusi cara sumuran. Parameter yang digunakan pada penentuan aktivitas antibakteri yaitu zona hambat yang terbentuk. Konsentrasi yang digunakan adalah $5 \% \mathrm{~b} / \mathrm{v}$, $10 \% \mathrm{~b} / \mathrm{v}, 20 \% \mathrm{~b} / \mathrm{v}, 40 \% \mathrm{~b} / \mathrm{v}, 60 \% \mathrm{~b} / \mathrm{v}, 80 \% \mathrm{~b} / \mathrm{v}$. Uji aktivitas dilakukan dengan cara menambahkan ekstrak di lubang pada media yang telah diberi suspensi bakteri Staphylococcus aureus, kemudian diinkubasi pada suhu $37^{0} \mathrm{C}$ selama 24 jam. Dari hasil pengujian didapat zona hambat 5\% adalah 7,00mm, 10\% adalah 8,30mm, 20\% adalah $9,60 \mathrm{~mm}, 40 \%$ adalah $11,00 \mathrm{~mm}, 60 \%$ adalah $12,33 \mathrm{~m}$ dan $80 \%$ adalah $14,33 \mathrm{~mm}$.
\end{abstract}

Kata Kunci : Antibakteri, kulit bawang merah, zona hambat, Staphylococcus aureus

\begin{abstract}
One of the plants tat used in medicine is garlic (Allium cepa L.). In addition as medicinal traditional plant, garlic is used as food spice. Garlic utillizated for the root only, and the skin which is rich with fibrous and flavonoid is wasted. This research aim is to know if the garlic skin have antibacterial activity against Staphylococcus aureus. Garlic skin made into extract with maseration methode using 96\% ethanol.Antibacterial activity test with hollow diffusion methode. Te parameter used are inhibition zone created. Variation of concentration are $5 \% \mathrm{~b} / \mathrm{v}, 10 \% \mathrm{~b} / \mathrm{v}, 20 \% \mathrm{~b} / \mathrm{v}, 40 \% \mathrm{~b} / \mathrm{v}, 60 \% \mathrm{~b} / \mathrm{v}, 80 \% \mathrm{~b} / \mathrm{v}$. Activity test made with extract added in the hole in the Staphylococcus aureus media, then incubated at temperature $37^{\circ} \mathrm{C} 24$ hours. The inhibition zone $5 \%, 10 \%, 20 \%, 40 \%, 60 \%$, and $80 \%$ extract respectively were $7,00 \mathrm{~mm}, 8,30 \mathrm{~mm}, 9,60 \mathrm{~mm}, 11,00 \mathrm{~mm}, 12,33 \mathrm{~m}$ and $14,33 \mathrm{~mm}$.
\end{abstract}

Keywords : Antibacterial, garlic skin, inhibition zone, Staphylococcus aureus

*Coresponding author : Khusnul Diana, khusnul_diana@yahoo.com (ph:+62-821-5568-0815) 


\section{PENDAHULUAN}

Bawang merah (Allium cepa L.) merupakan salah satu jenis sayuran yang banyak digunakan oleh masyarakat Indonesia. Sebagai salah satu komoditas sayuran yang secara ekonomis menguntungkan dan mempunyai prospek pasar yang luas, bawang merah cukup banyak digemari oleh masyarakat, terutama sebagai bumbu penyedap masakan, namun dapat pula sebagai bahan obat, seperti: untuk menurunkan kadar kolesterol, sebagai obat terapi, antioksidan, dan antimikroba (Randle, 1997 dan Havey, 1999).

Bawang merah memiliki karakteristik senyawa kimia, yaitu senyawa kimia yang dapat merangsang keluarnya air mata jika bawang merah tersebut disayat pada bagian kulitnya dan senyawa kimia yang mengeluarkan bau yang khas (Lancaster and Boland,1990).

Salah satu penghasil bawang merah yaitu Kota Palu, Sulawesi Tengah yang menjadi penghasil oleh-oleh bawang merah, karena pengetahuan masyarakat yang terbatas tentang pemanfaatan kulit bawang merah yang dapat digunakan sebagai antibakteri dan dapat menyembuhkan penyakit-penyakit lainnya. Bawang merah mempunyai kandungan sulfur compound seperti Allyl Propyl Disulphida (APDS) dan flavonoid seperti quercetin yang dipercaya bisa mengurangi resiko kanker, penyakit jantung dan kencing manis. Kulit bagian luar bawang yang mengering dan kerap berwarna kecoklatan kaya serat dan flavonoid serta antibakteria terhadap Stapylococcus aureus dan E. coli (Harsawardana.S, 2011).

Bakteri Staphylococcus aureus merupakan bakteri yang hidup dipermukaan tubuh individu sehat tanpa membahayakan, terutama sekitar hidung, mulut, alat kelamin, dan rectum. Namun, ketika kulit kita mengalami luka atau tusukan, bakteri ini akan masuk melalui luka dan menyebabkan infeksi. (Jawetz et al.,1995).

Dari paparan diatas maka perlunya dilakukan penelitian mengenai aktifitas antibakteri ekstrak kulit bawang merah (Allium cepa L.) terhadap Stapylococcus aureus.

\section{METODE PENELITIAN Jenis penelitian}

Jenis penelitian ini yaitu penelitian kualitatif dengan metode pendekatan eksperimental laboratorium untuk mengetahui aktifitas antibakteri ekstrak kulit bawang merah terhadap Staphylococcus aureus .

\section{Waktu dan tempat Penelitian}

Penelitian ini dilaksanakan pada bulan Juni sampai dengan Agustus 2015. Penelitian ini dilakukan di Laboratorium Kesehatan dan Akademi Farmasi Tadulako Farma Palu.

\section{Jenis dan Sumber Data}

Jenis data yang diperoleh berupa data primer dari hasil penelitian laboratorium dan juga data sekunder yang didapat dari berbagai sumber. Data-data tersebut berupa dokumen, laporan dan bahan-bahan lain secara tertulis dan relevan mengenai aktifitas antibakteri ekstrak kulit bawang merah terhadap Staphylococcus aureus.

\section{Tehnik Pengumpulan Data}

Data yang diperoleh untuk penyusunan Karya Tulis Ilmiah ini berasal dari pustaka, pengambilan bahan, dan hasil penelitian secara langsung.

\section{Instrumen Penelitian}

Alat

Alat-alat yang digunakan dalam penelitian adalah autoclave, batang pengaduk, beker gelas $1000 \mathrm{ml}$ (Pirex), lubang tips atau pencadang, cawan petri (Pirex), erlenmeyer $200 \mathrm{ml}$ (Pirex), gelas ukur $100 \mathrm{ml}$ (Pirex), inkubator (Mammert), karet gelang, Laminer Air Flow (Eyela), lampu bunsen, ose, oven, pipet tetes, pipet mikro, kapas lidi steril, tabung reaksi, wadah maserasi, rotavapor,

\section{Bahan}

Bahan yang digunakan dalam penelitian ini adalah alumunium foil, $\mathrm{NaCl}$ fisiologi $96 \%$, aquadest, kulit bawang merah, etanol 95\%, Stapylococcos aureus, kapas, kertas HVS, kertas saring, nutrient agar.

\section{Sterilisasi Alat}

Alat-alat kaca seperti beker gelas, gelas ukur, erlenmeyer, dan tabung reaksi, cawan petri, cakram kertas steril, batang pengaduk dibungkus dengan kertas HVS. Kemudian alatalat tersebut dimasukkan ke dalam oven dengan suhu $180^{\circ} \mathrm{C}$ selama 1 jam. Ose disterilisasi dengan cara dibakar di atas lampu bunsen sampai pijar. 


\section{Proses Pengolahan Simplisia}

Diambil kulit bawang merah yang segar, kulit bawang merah segar akan disortasi basah, kemudian kulit yang telah disortasi basah dicuci dengan air mengalir. Setelah disortasi basah kulit bawang merah di potong kecilkecil (dirajang), kulit bawang merah yang sudah dipotong kecil-kecil kemudian dikeringkan dengan cara diangin-anginkan. Setelah kulit bawang merah dikeringkan dilakukan sortasi kering terhadap kulit bawang yang mengalami kerusakan pada saat proses pengeringan. Kulit bawang merah yang telah disortasi kering kemudian siap di ekstraksi.

\section{Proses Ekstraksi}

Penelitian ini menggunakan metode ekstraksi maserasi. Ditimbang simplisia seberat 50 gram, Simplisia direndam di dalam wadah maserasi yang telah berisi cairan penyari yaitu etanol $96 \%$ sebanyak 8 Liter selama 3 hari dan sesekali diaduk. Setelah diperoleh ekstrak dari perendaman ekstrak tersebut dirotavapor untuk memperoleh ekstrak kental.

\section{Pembuatan Variasi Konsentrasi}

Ekstrak kulit bawang merah yang diuji untuk menghambat atau membunuh pertumbuhan bakteri Staphylococcus aureus dibuat dalam beberapa konsentrasi yaitu konsentrasi $5 \%$ b/v, konsentrasi $10 \%$ b/v, konsentrasi $20 \% \mathrm{~b} / \mathrm{v}$, konsentrasi $40 \% \mathrm{~b} / \mathrm{v}$, konsentrasi $60 \%$ b/v, konsentrasi $80 \%$ b/v.

\section{Pembuatan Media Nutrient agar (Plating)}

Ditimbang seberat 15 gram nutrient agar dan dimasukkan ke dalam Erlenmeyer, ditambahkan dengan $1000 \mathrm{ml}$ aquadest, lalu dipanaskan di atas hot plate hingga mendidih sambil diaduk sampai homogen. Kemudian media disterilisasi dengan cara bagian mulut erlenmeyer ditutup dengan kapas dan dengan kertas yang diikat dengan karet gelang, kemudian dimasukkan ke dalam autoclave selama 15 menit pada suhu $121^{\circ} \mathrm{C}$. Tuang media steril ke dalam cawan petri steril secara aseptis didalam LAF.

\section{Inokulasi Bakteri (Peremajaan)}

Inokulasi bakteri adalah menumbuhkan bakteri dalam tabung reaksi agar yang telah dibuat.Cara yang dilakukan dalam inokulasi bakteri adalah:
Diambil 1 ose bakteri dan digoreskan dimedia agar miring, lalu diinkubasi selama 24 jam.

\section{Pembuatan suspensi bakteri}

Membuat larutan suspensi bakteri Staphylococcus aureus diambil 1 ose bakteri, dimasukkan kedalam tabung reaksi yang berisi $10 \mathrm{ml}$ larutan $\mathrm{NaCl}$ fisiologi $0,9 \%$, dengan biakan murni Staphylococcus aureus didalam tabung reaksi dikocok sampai homogen, kemudian disamakan dengan standar $\mathrm{Mc}$ Farland.

\section{Perlakuan}

Penentuan aktifitas antibakteri Staphylococcus aureus dilakukan dengan menggunakan metode difusi dengan cara sumuran. Prosedurnya yaitu:

a. Dibuat sumuran pada media agar yang telah dipadatkan dengan menggunakan alat lubang tips atau pencadang

b. Diberi label pada masing-masing lubang sumuran dengan masing-masing konsentrasi serta control negative dan positif

c. Setelah diberi label dimasukkan ekstrak kedalam lubang sumuran pada masingmasing konsentrasi, perlakuan ini diulang sebanyak tiga kali

d. Cawan agar diinkubasi selama 1x24 jam pada suhu $37^{\circ} \mathrm{C}$

e. Setelah diinkubasi, zona hambatan yang terbentuk diamati dan diukur.

\section{Uji Aktifitas Antibakteri dengan Metode Sumuran}

Penentuan aktivitas antibakteri

Staphylococcus aureus dilakukan dengan metode difusi agar menggunakan cara sumuran.

\section{Teknik Analisis}

Perhitungan statistik data diameter zona hambat ekstrak kulit bawang merah (Allium cepa L.) terhadap pertumbuhan Staphylococcus aureus menggunakan Rancangan Acak Lengkap (RAL) (Sastrosupadi, 1995).

\section{HASIL DAN PEMBAHASAN Hasil}

Hasil pengujian ekstrak kulit bawang merah (Allium cepa L.) terhadap bakteri Staphylococcus aureus yang ditumbuhkan pada media nutrien agar ternyata menunjukan 
kemampuan yang berbeda disetiap konsentrasi yang diberikan dan dilakukan uji pendahuluan kandungan zat aktif dari ekstrak kulit bawang merah (Allium cepa L.) dapat dilihat pada tabel di bawah ini :

Tabel 1. Uji kandungan ekstrak kulit bawang merah menggunakan metode reaksi warna

\begin{tabular}{|c|c|c|c|c|}
\hline No & Zat Aktif & Hasil Teori & Hail Uji & Ket \\
\hline 1 & Flavanoid & Merah & Merah & + \\
\hline 2 & Tanin & $\begin{array}{c}\text { Kehijau- } \\
\text { hijauan }\end{array}$ & $\begin{array}{c}\text { Hehijam } \\
\text { hijauan }\end{array}$ & + \\
\hline 3 & Saponin & Ada busa & $\begin{array}{c}\text { Tidak ada } \\
\text { busa }\end{array}$ & - \\
\hline
\end{tabular}

Tabel 2.Diameter zona hambat ekstrak kulit bawang merah terhadap Stapylococcus aureus dengan metode sumuran.

\begin{tabular}{|l|c|c|c|c|c|}
\hline \multirow{2}{*}{$\begin{array}{c}\text { Konse } \\
\text { ntrasi }\end{array}$} & \multicolumn{2}{|c|}{ Ulangan (mm) } & \multirow{2}{*}{ Total } & $\begin{array}{c}\text { Rata- } \\
\text { rata } \\
(\mathbf{m m})\end{array}$ \\
\cline { 2 - 5 } $\mathbf{8 0 \%}$ & 15,00 & 14,00 & 14,00 & 43,00 & 14,33 \\
\hline $\mathbf{6 0 \%}$ & 12,00 & 13,00 & 12,00 & 37,00 & 12,33 \\
\hline $\mathbf{4 0 \%}$ & 10,00 & 12,00 & 11,00 & 33,00 & 11,00 \\
\hline $\mathbf{2 0 \%}$ & 8,00 & 11,00 & 10,00 & 29,00 & 9,60 \\
\hline $\mathbf{1 0 \%}$ & 6,00 & 10,00 & 9,00 & 25,00 & 8,30 \\
\hline $\mathbf{5 \%}$ & 5,00 & 8,00 & 9,00 & 21,00 & 7,00 \\
\hline K (-) & 0 & 0 & 0 & 0 & 0 \\
\hline K (+) & 21,00 & 21,00 & 21,00 & 63,00 & 21,00 \\
\hline
\end{tabular}
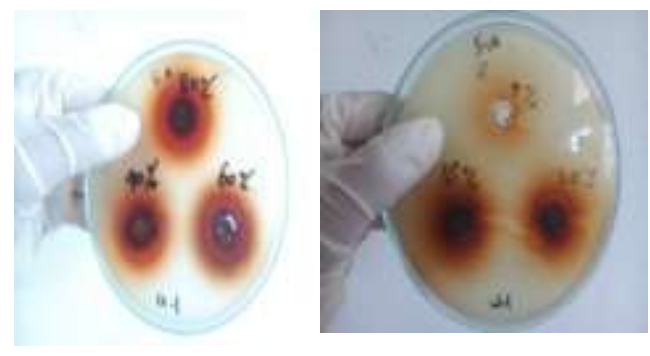

Gambar 1. Zona hambat ekstrak kulit bawang merah terhadap Staphylococcus aureus Perlakuan I

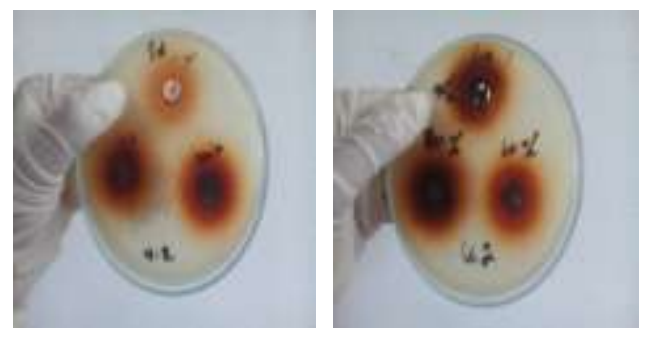

Gambar 2. Zona hambat ekstrak kulit bawang merah terhadap Staphylococcus aureus Perlakuan

II
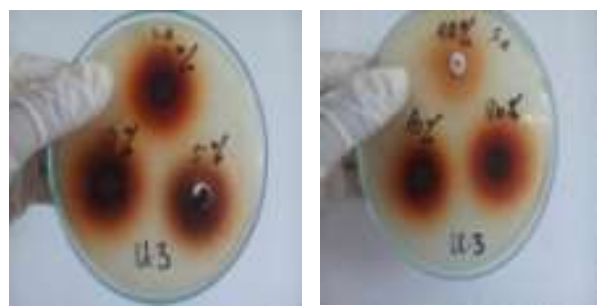

Gambar 3. Zona hambat ekstrak kulit bawang merah terhadap Staphylococcus aureus Perlakuan III

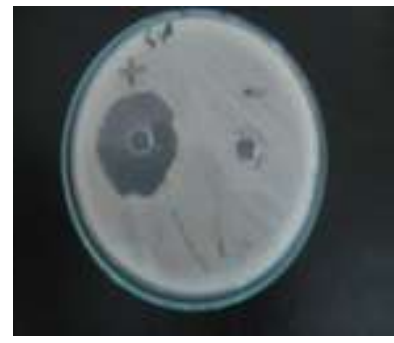

Gambar 4. Kontrol positif dan negatif

Tabel 3. Hasil analisis zona hambat ekstrak kulit bawang merah (Allium cepa L.) terhadap Staphylococcus aureus dengan metode cara sumuran.

\begin{tabular}{|c|c|c|c|c|c|}
\hline $\begin{array}{c}\text { SK } \\
\text { (Sumber } \\
\text { Keberagaman) }\end{array}$ & $\begin{array}{c}\text { DB } \\
\text { (Derajat } \\
\text { Bebas) }\end{array}$ & $\begin{array}{c}\text { JK } \\
\text { (Jumlah } \\
\text { Kuadrat) }\end{array}$ & $\begin{array}{c}\text { KT } \\
\text { (Kuadrat } \\
\text { Tengah) }\end{array}$ & \multirow{2}{*}{$\begin{array}{c}\text { F. } \\
\text { Hit }\end{array}$} & $\begin{array}{c}\text { F. } \\
\text { Tabel }\end{array}$ \\
\cline { 1 - 4 } Perlakuan & 3 & 394,283 & 65,713 & \multirow{2}{*}{40,} & \multirow{2}{*}{5,95} \\
\hline Galat & 14 & 22,677 & 1,619 & \multirow{2}{*}{588} & \\
\hline Total & & 416,96 & 67,332 & & \\
\hline
\end{tabular}

Berdasarkan hasil pengujian F. Hitung pada analisis sidik ragam menunjukan perbedaan yang sangat nyata. 


\section{Pembahasan}

Setelah dilakukan penelitian terhadap ekstrak kulit bawang merah (Allium cepa L.) terhadap Staphylococcus aureus diperoleh hasil bahwa ekstrak kulit bawang merah mempunyai daya hambat terhadap pertumbuhan bakteri dengan melihat adanya zona hambat disekeliling ekstrak yang telah di buat cara sumuran dan membandingkan sampel tersebut dengan antibiotik golongan penisilin.

Adapun cara sterilisasi alat meliputi alat-alat kaca seperti beker gelas, gelas ukur, Erlenmeyer, dan tabung pereaksi, cawan petri pencadang, batang pengaduk dibungkus dalam kertas HVS. Kemudian alat-alat tersebut dimasukkan kedalam oven dengan suhu $180^{\circ} \mathrm{C}$ selama 1 jam. Ose disterilisasi dengan cara dibakar diatas lampu bunsen sampai pijar. Prinsip kerja sterilisasi dengan uap panas kering yaitu oven protein mikroba akan mengalami dehidrasi hingga terjadi kekeringan, selanjutnya teroksidasi oleh oksigen diudara sehingga menyebabkan matinya mikroba dan tidak menimbulkan embun/ kondensasi pada alat yang disterilisasi serta sterilisasi media nutrient agar menggunakan sterilisasi uap yaitu autoclave, prinsip kerjanya yaitu mikroba akan mengalami denaturasi dan koagulasi yang menyebabkan mikroba tersebut mati.

Hal pertama yang dilakukan yaitu menggambil bahankulit bawang merah yang segar, lalu disortasi basah, setelah disortasi basahkemudian dicuci bersih dengan menggunakan air yang mengalir sehingga kotoran yang terdapat pada bahan tersebut hilang. Setelah itu dilakukan pengubahan bentuk dengan cara dipotong kecil-kecil atau dirajang, lalu dikeringkan dengan cara diangin-anginkan, setelah kulit bawang merah dikeringkan dilakukan sortasi kering terhadap kulit bawang yang mengalami kerusakan pada proses pengeringan. Kulit bawang yang telah disortasi kering kemudian siap untuk diekstraksi.

Pada uji pendahuluan untuk mengetahui kandungan kimia dari ekstrak kulit bawang merah menggunakan metode reaksi warna diperoleh hasil yaitu ekstrak kulit bawang merah positif mengandung flavanoid dan tanin sedangkan untuk uji saponin diperoleh hasil negative.

Proses ekstraksi menggunakan metode maserasi alasannya karena lebih mudah dalam pengerjaanya, alat yang digunakan lebih sederhana dan ekstrak yang diperoleh tidak mudah ditumbuhi kapang atau khamir. Dalam proses maserasi yang dilakukan yaitu menimbang simplisia seberat 50 gram, simplisia direndam menggunakan 3 wadah (toples) maserasi yang telah berisi cairan penyari yaitu etanol $96 \%$ sebanyak 8 liter masing-masing wadah 2,5 liter pelarut selama 3-5 hari dan sesekali diaduk. Setelah diperoleh ekstrak dari perendaman tersebut dirotavapor untuk memperoleh ekstrak kental, ekstrak kental yng diperoleh yaitu sebanyak 16,62 gram. Alasan penggunaan pelarut etanol $96 \%$ yaitu bersifat lebih selektif yaitu hanya menarik zat berkhasiat yang dikehendaki, absorbsinya baik, kapang dan khamir sulit tumbuh, mudah menguap dan mendapatkan ekstrak kental lebih cepat dibandingkan pelarut etanol $70 \%$.

Metode yang digunakan dalam penelitian ini adalah metode difusi cara sumuran dengan menggunakan lubang tips atau pencadang untuk membuat lubang pada media Nutrient agar yang telah padat dan ditambahkan suspensi bakteri dengan cara sebar mengguankan kapas lidi steril. Setelah lubang terbentuk kemudian dimasukkan ekstrak yang telah dibuat dengan masingmasing konsentrasi. Alasan pengguanaan metode difusi ndengan cara sumuran yaitu ekstrak langsung dimasukkan disetiap lubang maka efek untuk menghambat bakteri lebih kuat. Pada metode sumuran terjadi proses osmolaritas dari konsentrasi ekstrak yang lebih tinggi dari metode difusi disk, setiap lubang diisi dengan konsentrasi ekstrakmaka osmolaritas terjadi lebih menyeluruh dan lebih homogen serta konsentrasi ekstrak lebih kuat dan lebih tinggi untuk menghambat pertumbuhan bakteri. (Novel dkk)

Pada pengamatan dan pengukuran zona hambat dilakukan pada hari pertama ( 24 jam) zona hambat terbentuk. Untuk mengetahui apakah ekstrak kulit bawang merah memiliki sifat bakterisid maka dilakukan pengamatan zona hambat dilanjutkan selama 48 jam. Setelah diamati pada 48 jam bakteri tidak tumbuh pada daerah hambat. Hal ini menunjukan bahwa ekstrak kulit bawang merah dapat membunuh bakteri (bakterisid).Dari penjelasan tersebut bahwa ekstrak kulit bawang merah bersifat bakteriostatik dan bakterisid terhadap bakteri Staphylococcus aureus. 
Uji ekstrak dibuat dalam beberapa konsentrasi yaitu $80 \%$ b/v, 60\% b/v, $40 \%$ b/v, $20 \%$ b/v, $10 \% \mathrm{~b} / \mathrm{v}, 5 \% \mathrm{~b} / \mathrm{v}$, untuk mengetahui KHM dari ekstrak kulit bawang merah, aquadest sebagai kontrol negative dan ampicilin sebagai kontrol positif sebagai pembanding terhadap hasil ekstrak yang diujikan. Hal ini dilakukan untuk mengetahui pada konsentrasi berapa ekstrak kulit bawang merahdapat memberi efek antibakteri yang paling efektif dengan ditandai adanya zona hambat.

Media yang digunakan untuk pertumbuhan bakteri yaitu media nutrient agar yang merupakan salah satu media umum yang digunakan dalam prosedur bakteriologi seperti uji biasa dari air, sewage, produk pangan, untuk membawa stok kultur, untuk pertumbuhan sampel uji pada bakteri, dan untuk mengisolasi organisme dalam kultur murni.

Hasil pada tabel 4.2 menunjukan bahwa adanya perbedaan daerah hambat yang terbentuk pada masing- masing perlakuan , dimana dilakukan sebanyak 3 kali ulangan. Rata- rata daerah hambat tersebut menunjukan bahwa adanya perubahan yang terjadi terhadap pertumbuhan bakteri Staphylococcus aureus dari zat aktif dalam ekstrak kulit bawang merah yang digunakan sebagai sampel. Pada perlakuan kontrol positif dengan menggunakan ampicillin, dalam hal ini kontrol antibiotik ampicillin memperlihatkan rata-rata zona hambat yang yang lebih besar dibandingkan dengan sampel uji.Hal ini terjadi karena ampicilinsebagai kontrol positif pada uji aktivitas antimikroba karena penisilin merupakan antibiotik yang sering digunakan.Penisilin $\mathrm{G}$ merupakan obat pilihan untuk infeksi yang disebabkan oleh bakteri gram positif aerob, streptokokus, pneumokokus, meningokokus, spiroketha, klostridia, stafilokokus, danaktinomices yang bukan penghasil penicilase.(Jawet et al., 2005) Dalam Tabel 4.2, perlakuan dengan konsentrasi $0 \%$ (kontrol negatif) yang menggunakan aquadest steril menunjukan bahwa kontrol tidak memperlihatkan adanya zona hambat yang terbentuk, ini terjadi karena aquadest merupakan senyawa netral yang tidak mengandung racun ataupun zat-zat yang dapat menghambat dan membunuh pertumbuhan bakteri Staphylococcus aureus.

Berdasarkan pada gambar 4.2,menunjukan bahwa pada konsentrasi terendah yaitu $(5 \% \mathrm{~b} / \mathrm{v})$ masih memiliki daya hambat yang ditujukan dengan terbentuknya zona hambat.

Terbentuknya zona hambat seperti yang diganbarkan dalam grafik(gambar 4.1), menunjukan bahwa ekstrak kulit bawang merah (Allium cepa L.) mampu menghambat pertumbuhan bakteri Staphylococcus aureus. Dari hasil penelitian menunjukan bahwa diameter zona hambat terbentuk dimulai pada konsentrasi 5\% adalah sebesar 7,00 mm, kemudian pada konsentrasi $10 \%$ sebesar 8,30 $\mathrm{mm}$, konsentrasi $20 \%$ yaitu $9,60 \mathrm{~mm}$, konsentrasi $40 \%$ yaitu $11,00 \mathrm{~mm}$, konsentrasi $40 \%$ yaitu $12,33 \mathrm{~mm}$, konsentrasi $60 \%$ yaitu 14,33, konsentrasi $80 \%$ yaitu $21,00 \mathrm{~mm}$ sedangkan perlakuan kontrol positif dengan menggunakan cara sumuran yang berisi larutan Ampicillin, zona hambat yang terbentuk sebesar 21,00 $\mathrm{mm}$.

Dari penguatan hipotesis dilakukan perbandingan antara $\mathrm{F}$ hitung dengan $\mathrm{F}$ tabel daya hambat ekstrak kulit bawang merah (Allium cepa L.) pada tabel 4.2 menunjukan bahwa hasil F. hitung lebih besar dari F tabel , dimana nilai $\mathrm{F}$ hitung yaitu 40,88 sedangkan $\mathrm{F}$ tabel 5,95 (1\%). Dengan demikian $\mathrm{H}_{0}$ ditolak dan $\mathrm{H}_{1}$ diterima, yaitu terdapat pengaruh berbeda nyata dari semua konsentrasi ekstrak kulit bawang merah (Allium cepa L.) terhadap terbentuknya daerah hambat pada bakteri Staphylococcus aureus.Jadi terdapat perbedaan perlakuan terhadap pertumbuhan bakteri Staphylococcus aureus pada masing-masing konsentrasi.

\section{DAFTAR PUSTAKA}

Anonim. (1979). Farmakope Indonesia, edisi III. Departemen Kesehatan Republik Indonesia; Jakarta.

Dwidjoseputro.D, (1994). Dasar-Dasar Mikrobiologi, Djambatan, Jakarta

Ganiswarna, S.G. (1995). Farmakologi dan terapi, edisi IV (cetak ulang 2006). Gaya Baru ;Jakarta

Jawetz, et al. (2005). Mikrobiologi Kedokteran, Edisi 23, Alih Bahasa Huriwati Hartanto, Penerbit Buku Kedokteran ECG; Jakarta.

Khusan, Pritiyantoro, W., \& Slipranata, M. (2012). Identifikasi dan Karakteristik 
Fenotipe Staphylococcus Aureus asal Kasus Bumblefoot dan Arthritis Pada Boiler, J Kedokteran Hewan, VI(2).

Manullang, L. (2010). Karakterisasi Simplisia, Skrining Fitokimia dan Uji Toksisitas Ekstrak Kulit Umbi Bawang Merah (Alliicepaevar. Ascalonicum) dengan metode uji Brine Shrimp Test (BST). Universitas Sumatera Utara Press. Medan.
Sastrosupadi, A. (1995). Rancangan Percobaan Praktis Untuk Bidang Pertanian, Kamisius, Jakarta

Soebagio, B., Rusdiana, T., \& Khairudin. (2007). Pembuatan Gel Dengan Aqupec HV-505 dari Ekstrak Umbi Bawang Merah (Allium cepa, L.) sebagai Antioksidan. Fakultas Farmasi, Universitas Padjadjaran. Bandung.

Syamsuni. (2007). Ilmu Resep, Buku Kedokteran, Jakarta. 